\title{
System Design of Iris Ring Detection Using Circular Hough Algorithm for Iris Localization
}

\author{
ABDURAHMAN $^{1}$, SUTARNO $^{2 *}$, Rossi PASSARELLA ${ }^{2}$, Yosef PRIHANTO ${ }^{3}$, Rudy \\ A.G GULTOM ${ }^{1}$
}

\begin{abstract}
${ }^{I}$ Department of Sensing Technology Defense, Faculty of Technology Indonesia Defense University
${ }^{2}$ Department of Computer Systems, Faculty of Computer Science, Sriwijaya Universiti, Indonesia

${ }^{3}$ Department of Research, Geospatial Information Agency Indonesia (BIG), Indonesia

*Corresponding author: sutarno@unsri.ac.id
\end{abstract}

\begin{abstract}
Iris is the part of the eye that can expand and shrink depending on the intensity of light entering the eye. Iris can be used as a feature or parameter that can be studied in terms of both health and information technology. Detecting the iris in this paper, are separated into two main stages: preprocessing stage and iris detection stage which uses circular Hough transformation (CHT) algorithm), on the preprocessing image frame, the captured image will be cropped first, using ROI(region of interest) then grayscalling will take place on detection in edge detection with Canny operator, this is done in order to optimize circular Hough transformation (CHT) algorithm application in detection of iris, then in the second phase it will implement the results of applying the circular Hough transformation (CHT) algorithm with and without the OpenCV library.
\end{abstract}

Keywords: preprossesing, circular Hough transformation, region of interest, OpencvCV, grayscalling

\section{Introduction}

The use of computers in various disciplines emerge digital era that force us to use digital tools, the effect is quite significant in the fields of business and education, on the other hand, it also has some drawbacks if ones spend too long time when interacting with these devices. Iris recognition has become a popular research topic in recent years, because Iris recognition or iris feature extraction is not only serves as an identifier of a person's identity but can also present a state of one's health [1]. One method of extracting iris is using circular hough transformation (CHT) algorithm, using circular hough transformation (CHT) algorithm has an accuracy rate of $96.7 \%$ in detecting the iris [2].

Computer Vision Syndrome is a symptom or condition of the eye that causes by the use of computers if ones used it for too long, it is caused by a visual display terminal (VDT) which is part of the computer device, some of the symptoms caused by Computer Syndrome is asthenophic, eye dryness and visual impairments [3]. Working in front of the computer has not been proven to cause permanent eye damage, but the discomfort that caused by eyestrain affecting the productivity of a person performance by $40 \%$ decrement on certain tasks affected by Computer Syndrome [4].

Eyestrain is also influenced by the light factor where the person works such existing lighting level on research [5], that the lighting level of the workplace on that research is under the allowed standard that is equal to 96.16 lux, which is make a significant impact for eyestrain before and after work in the room where research is done, lack of lighting could worsen eyesight which porsionates eyes work and accelerated fatigue[5]. In this journal, researchers will discuss how the iris detection works as an indicator of a person's eye fatigue using circular hough transformation algorithm to recognize the length of iris diameter of a person which will then be taken on calculating the parameters of a person's eye fatigue.

\section{Methodelogy}

The following is a block diagram of the design software on the iris detection system as shown in Fig.1.

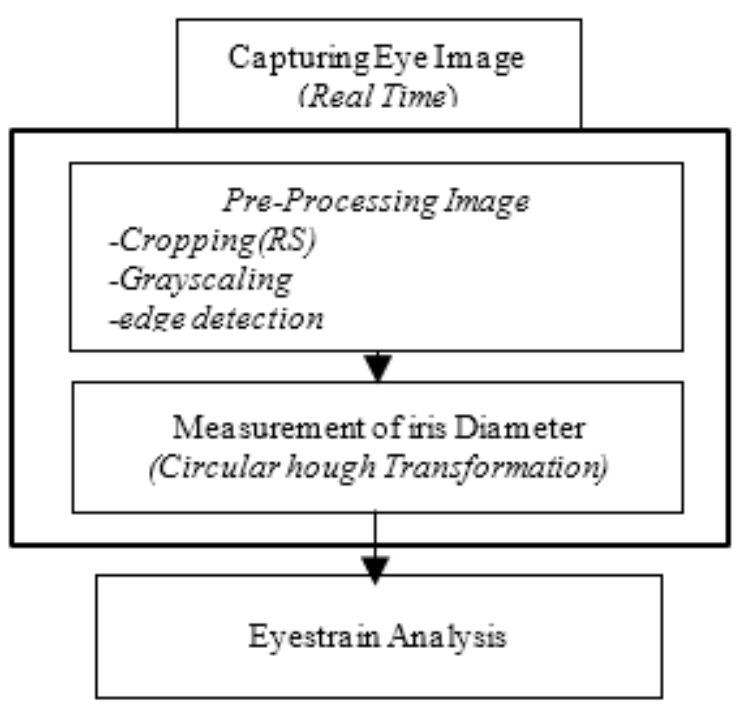

Figure 1. Block Diagram Desoign software Iris Ring Detection. 


\section{Capturing Eye Imagery}

At this stage the data sample to be taken is image of the eye with a webcam with the specified resolution. Camera will detect the sample in realtime.

\section{Cropping(Region Of Interest)}

Region splitting is doing the division of image since the begining into a preferred region, the region that is disjoint, then merge or split the region in an effort to reach certain conditions [6]. At this stage, we run the process of cropping the desired image area, eg RGB eye image that originally have a resolution of $320 \times 240$ pixel will be cropped in the middle of its area. This process is performed to remove the outer of the eye area such as the skin and so on, to minimalize error.

Here is the analogy of Region splitting as shown in Fig.2

\begin{tabular}{|l|l|l|}
\hline$R_{1}$ & \multicolumn{2}{|c|}{$R_{2}$} \\
\hline$R_{3}$ & $R_{41}$ & $R_{42}$ \\
\cline { 2 - 3 } & $R_{43}$ & $R_{44}$ \\
\hline
\end{tabular}

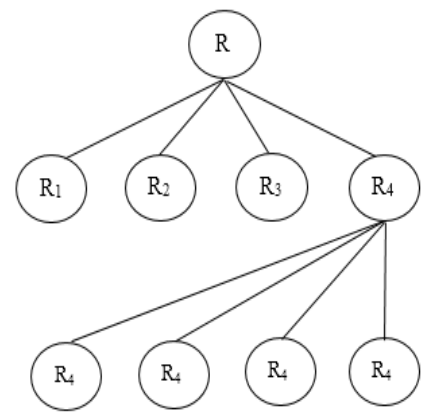

Figure 2. Region splitting.[6]

\section{Grayscaling}

Grayscale image is a digital image that has only one karnel value at each pixel in other words the value part red $=$ green $=$ blue. This value is used to indicate the level of intensity. Colors that is used are black, gray, and white. Level of grayness intensity are ranged from black to white. The following grayscale image has a color depth of 8 bits (256 color combinations gray)[7]. Results received by camera of the eye image after cropping process is still in a RGB image. In this process image that in a RGB format will be changed to grayscale format.

\section{Canny edge detection}

Canny Operator is well known as an optimal edge detection operator. This Algorithm provides a low error rate, able to localize edge dots (pixels within the edge found and edge detection are actually quite short), and only give one response to one edge[8]. The edges of the image is the position of a point $(x, y)$ in which the image pixel intensity changes from lower value to higher value or vice versa. After conducting grayscaling phase on eye image, the boundaries of the eye will be able to be detected.This method will detect the boundaries between the pupil and the surrounding area, Where the detection limit eye image taken by conducting Canny operations to eye image to be processed. Canny operator is an edge detection operator which has a minimum error rate, this is because the operator has the stage a bit more complex such applying the gausian filter, use the image in convolution sobel karnel and then seek for the value of the magnitude and direction of the corners towards pixel values of its neighbors, removing nonmax, as well as applying two tresholder to set a value of the threshold edge. Before performing detection, Canny operator should first channeled through the following steps.

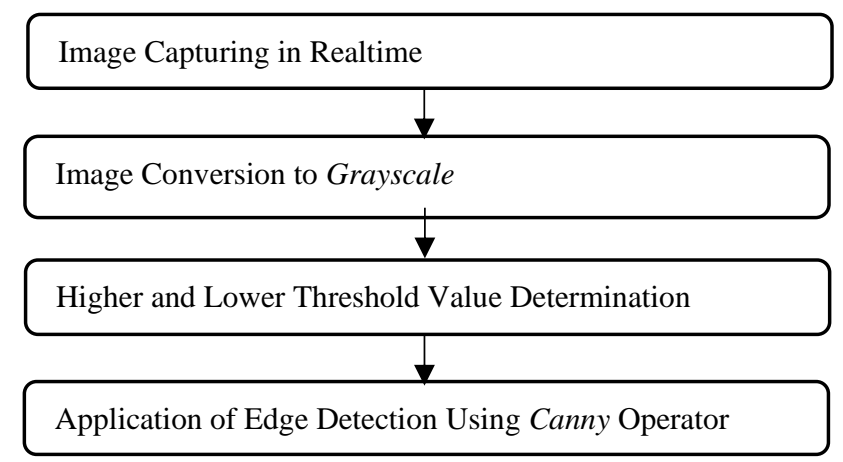

Figure 3. Several Step Canny Edge Detector

\section{Iris Diameter Measurement (Circular hough Transformation)}

The procedure used in detecting a circle is equal to the transformation hough on the line object, but worked on more complex space dimension that is within the parameters of $3 \mathrm{D}(\mathrm{x} 0, \mathrm{y} 0, \mathrm{r})$, where $\mathrm{x} 0$ and $\mathrm{y} 0$ is center coordinates of the circle and $\mathrm{r}$ is radius of the circle like in Eq.1 follows [9]:

$\left(\mathrm{x}-\mathrm{x}_{0}\right)^{2}+\left(\mathrm{y}-\mathrm{y}_{0}\right)=\mathrm{r}^{2}$

As for the vector its parameter is $\vec{P}=\left[\begin{array}{c}x^{0} \\ y^{0} \\ r\end{array}\right]$ and if it is on coordinates $\left(\mathrm{x}_{0}, \mathrm{y}_{0}, \mathrm{r}\right)$. With $\mathrm{R}$ is radius of the circle and ( $\mathrm{x}$, $\mathrm{y})$ are the coordinates of the center of the circle. If the center of the circle contained in (0.0), then the above equation can be written like Fig. 4

$$
x^{2}+y^{2}=R^{2}
$$

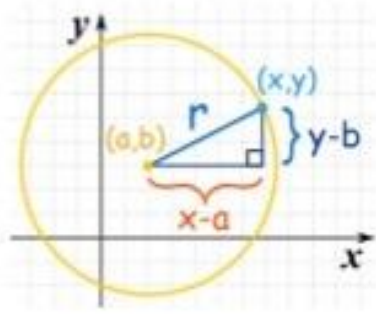

Figure 4. Circle Hough Transformation [10]

From fig. 4 The circle equation can also be formulated in a parametric equation can be written as below:

$\mathrm{x}=\mathrm{x}_{0}+\mathrm{R} \cos \theta$

$\mathrm{y}=\mathrm{y}_{0}+\mathrm{R} \sin \theta$ 
The application of cicular hough transformation algorithm applied to assist the calculation of diameter of pupil. In the application of this algorithm minimum and maximum value radius has been determined in advance and also detection of circle. And the object that being detected is still in a form of a circular image, and at this stage we will compare the results of detected circle with and without OpenCV. From the process of mathematic algorithm model then it produces the output an image in the form of circled circular object with a known center point and radius. For more details, following are the stages of the detection of the eye circle with circular hough transformation:

1. Preprocessing image, that is cropping (region of interest) toward the eye image. Then the eye image is converted to grayscale, then detecting the eye image edge with canny operator. This is done to optimalize the obtained result

2 . Determine the minimum and maximum values of radius of the object to be detected length of diameter.

3 . Each edges of the objects will be mapped by circle with every edges of the objects as the center point of the circle and at minimum distance and maximum radius that has been predetermined, and an array of data storage between the circles tangent on the edges of the objects will be provided. Objects that have the highest value of tangent is assumed to be the center of the circle.

4. The final stage is to illustrate the circular object on the begining image with the center point and radius that has been obtained

Fig.5.is an analogy circular detection using circular hough transformation (CHT) algorithm
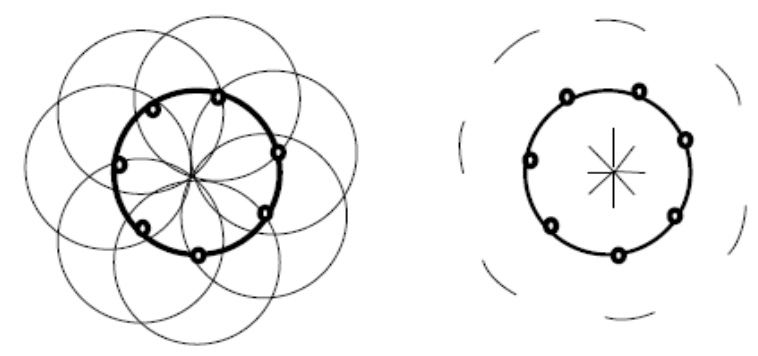

$7 \begin{aligned} & \text { Circle } \\ & \text { boundary }\end{aligned}$

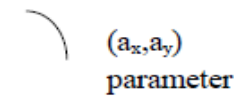
- Edge pixel

Figure 5. The CHT showing the edge points and accumulator[1].

\section{EXPERIMENT AND RESULTS}

The testing phase was conducted to determine the performance of the system built whether it run according to the design and the previous draft. Broadly, the system test in the present study will be divided into three processes, the image prepressing testing process, testing phase circular hough without libraries, testing phase circular hough with the library. In each process will be outlined further steps of every method that will be used. In this testing phase object that being detected still in the form circle marker.
The object to be detected by circular hough algorithm will be subject to several stages so that the system can detect the circle as well as it has been discussed before after successfully sampling the circle above, then we continue to detect the iris.

\section{Testing Capturing Sample}

Webcame will capture circular object with an image resolution of $320 \times 240$ pixels in realtime like the one in Fig.7.

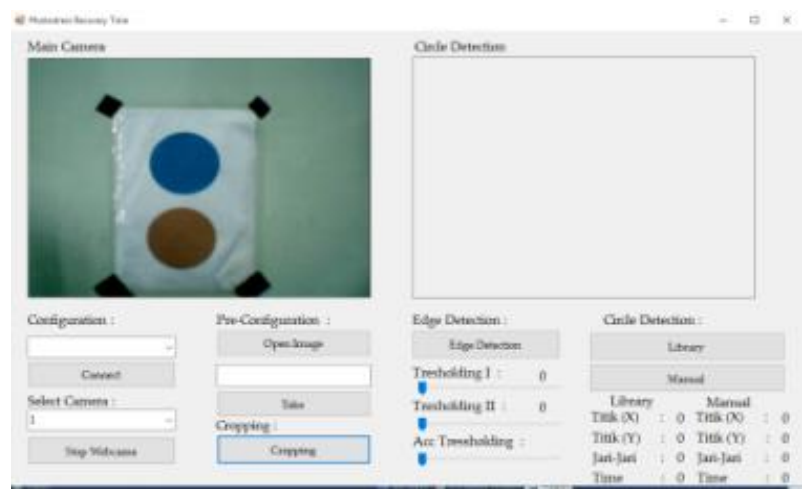

Figure 7. Image capturing in Real Time

\section{Testing Image Cropping}

Captured image (by webcam) will be in crop, cropping done to select the desired region and moved to the new image it aims to select the region near objects to reduce the error of circle detection. Camera takes pictures with a resolution of $320 \times 240$ pixels while at this stage the sample image is reduced by cutting a picture $90 \times 80$ pixels at a pixel position 100 on the $\mathrm{x}$-axis and 70 on the $\mathrm{y}$ axis. As for the results of region of interest to sample image as in Fig.8. below.

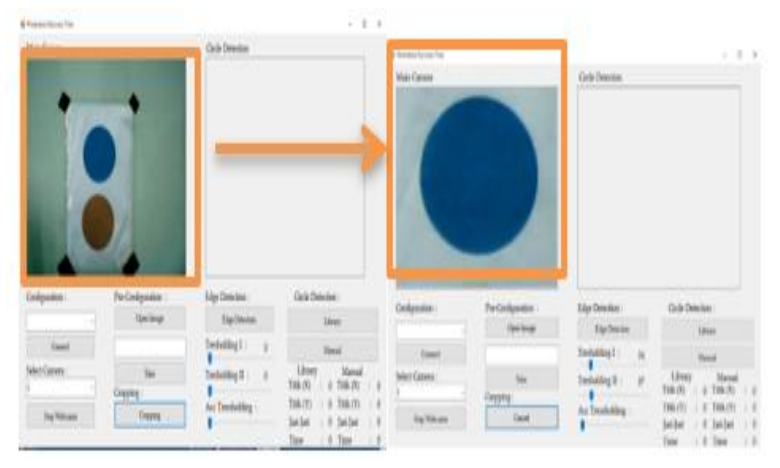

Figure 8. Cropping Image

In this system, cropping is used to localize the middle of the eye to minimize the background image of the sample, that sample images will be right in the middle of the eye.

\section{Testing Preprocessing Image}




\section{Testing Edge detection}

The object that has been cropped based on region of interest, the edges of the object will be detected by Canny operator, detection is done to select the object to be detected by the circle detection algorithm by looking for threshold I and II values. Tresholding will decide the edges of the objects from the image and hereinafter will be detected by the results of the circle edges following (Fig.9).

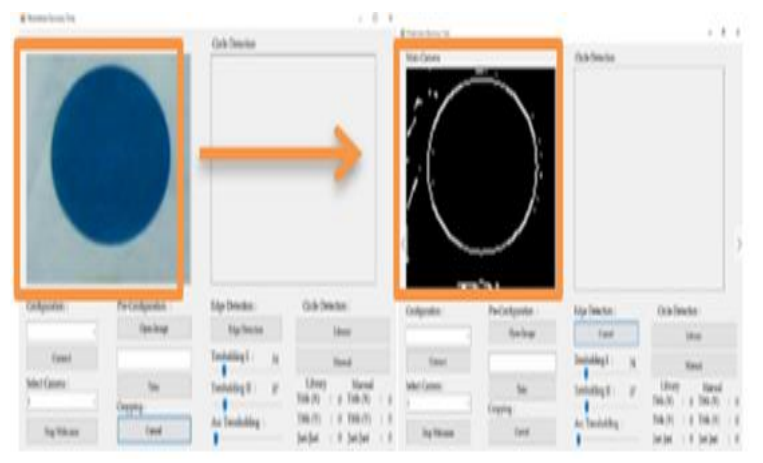

Figure 9. Edge detection

Tresholding searching process on the this systems uses a trackbar to determine the threshold value. As in the picture above the value of $\mathrm{T} 1=146$ and $\mathrm{T} 2=57$.

\section{Measuring Raidus and Center Point Objek in Matlab Phase}

Images are being analyzed its edge detection using tools "imtool" measure distance and use features such as the following figure:

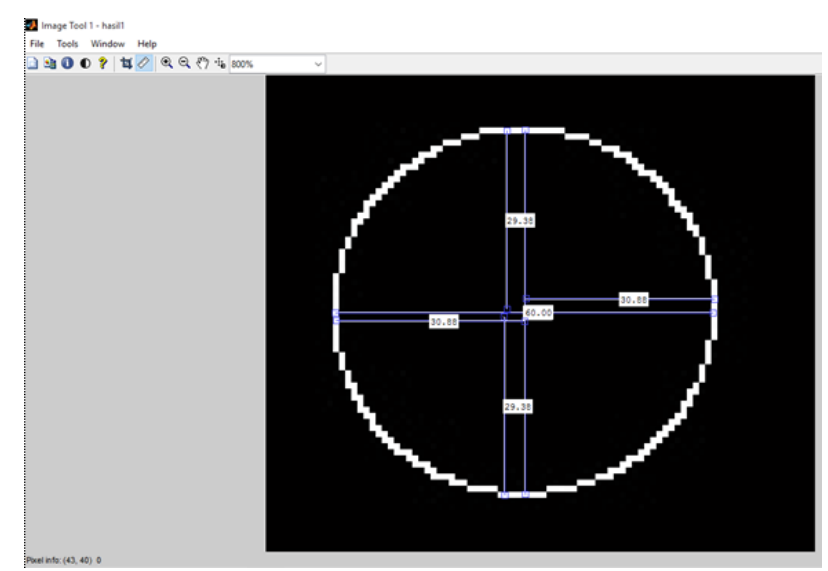

Fig.10. Image extraction in matlab

To determine the radius and the center point of the object in the image above, using the tool "imtool" feature measure distance that allows an interesting one point to another, so in this case would be a straight line vertically and horizontally to determine the diameter of the object, then will be sought its center point by dividing the diameter of either vertically or horizontally

\section{Measuring diffrent Radius Object beetwen Library and Without Library Phase}

The result data of edge detection will be detected by circle by calling the class OpenCV and without OpenCV to iterates circle in each images that has its edges detected. The results of the experiment at this stage listed on Table 1.

Table 1. Trial Measuring Radius Object

\begin{tabular}{|l|c|c|c|c|}
\hline \multirow{2}{*}{ No } & \multirow{2}{*}{ Image Result } & Library & Manual & Matlab \\
\cline { 3 - 5 } & & Radius & Radius & Radius \\
(pixel) & (pixel) & \\
\hline 1. & & 25 & 24 & 25 \\
\hline 2. & & 26 & 25 & 25 \\
\hline 3. & & 23 & 25 & 25 \\
\hline
\end{tabular}




\begin{tabular}{|c|c|c|c|c|}
\hline & & C Library & - Manual & Matlab \\
\hline No & Image Result & $\begin{array}{l}\text { Radius } \\
\text { (pixel) }\end{array}$ & $\begin{array}{l}\text { Radius } \\
\text { (pixel) }\end{array}$ & $\begin{array}{l}\text { Radius } \\
\text { (pixel) }\end{array}$ \\
\hline 4. & & 23 & 24 & 25 \\
\hline 5. & & 23 & 24 & 24 \\
\hline 6. & & 24 & 24 & 25 \\
\hline 7. & & 25 & 24 & 25 \\
\hline 8. & & 26 & 24 & 24 \\
\hline
\end{tabular}

The result of the detection of dark blue circle is a circle detection algorithm using manually while the green circle is a circle detection using OpenCV library assistance. At this stage it will be compared the results of the measurement using the library, no library and measurements manually per pixel in MATLAB. From all experiment results there is an error in the circle detection as for the calculation of the average error by using Eq.4 Error Relatif $=(\mid$ Measuring Result- Exactly Value $\mid /$ Exactly)Value x $100 \%$

Table 2. Measuring Radius Error

\begin{tabular}{|c|c|c|}
\hline Testing & $\begin{array}{c}\text { Measuring Euclidean } \\
\text { Distance of Center } \\
\text { Point Library }\end{array}$ & $\begin{array}{c}\text { Measuring Euclidean } \\
\text { Distance of Center } \\
\text { Point Manual }\end{array}$ \\
\hline 1. & $\frac{|25-25|}{25} \times 100 \%=0 \%$ & $\frac{|24-25|}{25} \times 100 \%=4 \%$ \\
\hline 2. & $\frac{|26-25|}{25} \times 100 \%=4 \%$ & $\frac{|25-25|}{25} \times 100 \%=0 \%$ \\
\hline 3. & $\frac{|23-25|}{25} \times 100 \%=4 \%$ & $\frac{|25-25|}{25} \times 100 \%=0 \%$ \\
\hline 4. & $\frac{|24-25|}{25} \times 100 \%=4 \%$ & $\frac{|25-25|}{25} \times 100 \%=0 \%$ \\
\hline 5. & $\frac{|23-25|}{25} \times 100 \%=8 \%$ & $\frac{|24-25|}{25} \times 100 \%=4 \%$ \\
\hline 6. & $\frac{|24-25|}{25} \times 100 \%=4 \%$ & $\frac{|24-25|}{25} \times 100 \%=4 \%$ \\
\hline 7. & $\frac{|25-24|}{24} \times 100 \%=4,16 \%$ & $\frac{|24-24|}{24} \times 100 \%=0 \%$ \\
\hline 8. & $\frac{|26-24|}{24} \times 100 \%=8,33 \%$ & $\frac{|24-24|}{24} \times 100 \%=0 \%$ \\
\hline
\end{tabular}


At this stage will be measured the radius of the eye on the sample with fresh eye condition. Fresh eye condition are eyes that have not interacted with the computer. The result of this experiment shown on Table 3.

Table 3. Measuring Radius Fresh Eye

\begin{tabular}{|c|c|c|}
\hline Testing & $\begin{array}{c}\text { Measuring Euclidean } \\
\text { Distance of Center } \\
\text { Point Library }\end{array}$ & $\begin{array}{c}\text { Measuring } \\
\text { Euclidean Distance } \\
\text { of Center Point } \\
\text { Manual }\end{array}$ \\
\hline 09121001006 & & \\
\hline 09121001003 & & \\
\hline & & \\
\hline & & \\
\hline & & \\
\hline
\end{tabular}

\section{Measuring Radius Eyestrain}

eyes that have interacted with the computer more than three hours. The result of this experiment shown on Table 4.

At this stage will be measured the radius of the eye on the sample with eyestrain condition. Eyestrain condition are

Table 4. Measuring Radius Eyestrain

\begin{tabular}{|c|c|c|}
\hline \multirow{7}{*}{ Testing } & Measuring & Measuring \\
& Euclidean Distance & Euclidean \\
of Center Point & Distance of \\
& Cibrary & Center Point \\
& & Manual \\
\hline
\end{tabular}




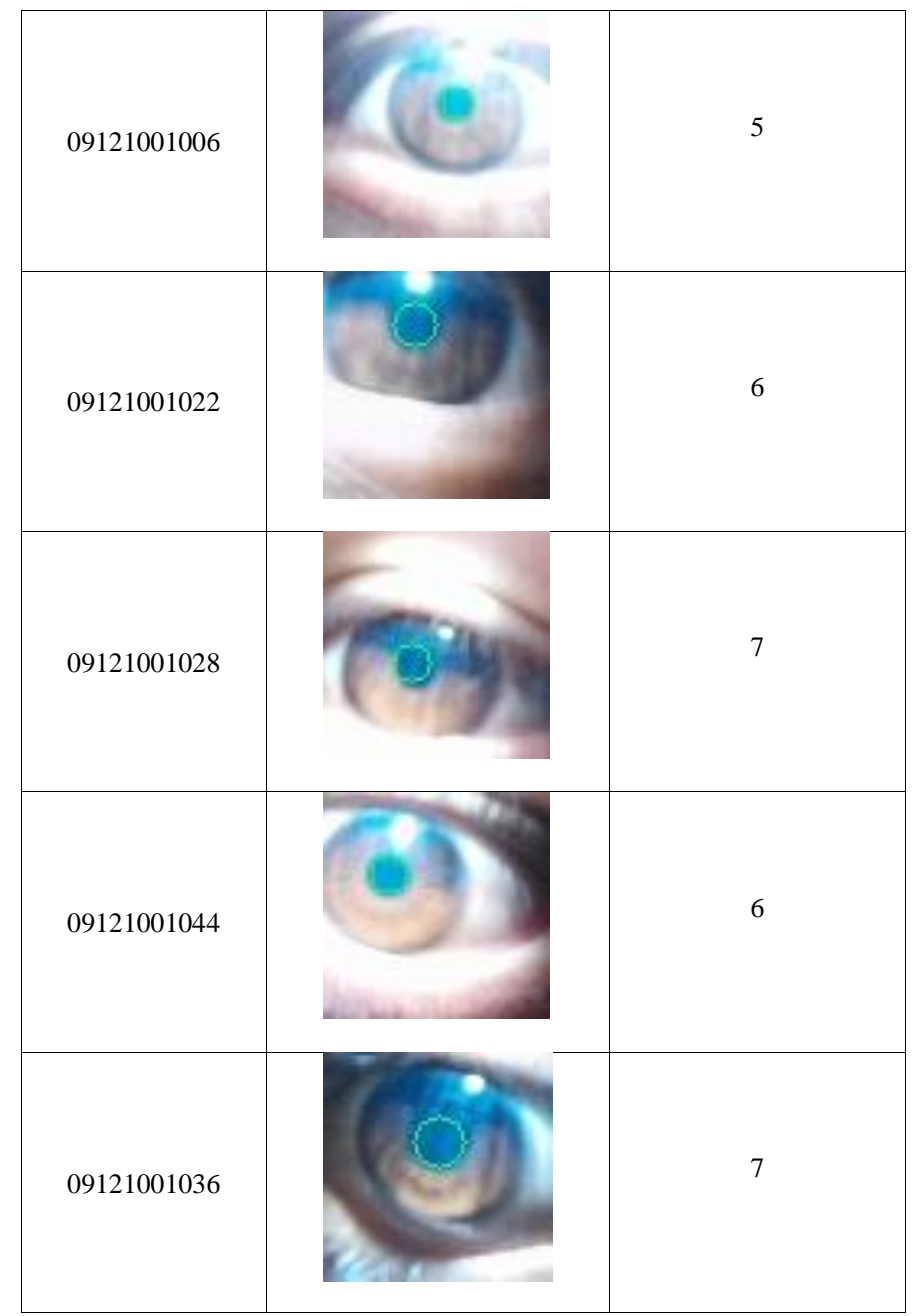

\section{CONCLUSION}

After testing and analyzing test results it can be concluded that:

Application of circular Hough algorithm can be applied to detecting a circular object or pupil.

Comparison of percentage of error based on the error value relative to the radius of the circle detection using the library has a lower value is $4,56 \%$ versus $1,5 \%$. Therefore, further research is recommended to use the library aid in the detection of objects

Comparison between manual and library algorithms have advantages and disadvantages of each, in terms of precision and speed circle detection algorithm is better manual on condition background circular object must be clean, while detection circle with library are not affected in any form the background of the object.

Acknowledgement

Many thanks to the Department of Computer System, Computer Science Faculty, University Sriwijaya and all of the peoples who supports this article.

\section{REFERENCES}

[1] Abdul Nor'aini Jalil, dkk, 2012, "Iris Localization Using Colour Segmentation and Circular Hough Transform”, International Conference on
Biomedical Engineering and Science'2012, Information.

[2] A. E. Yahya, M. J. Nordin, 2008, “A New Technique for Iris Localization”, International Scientific Conference Computer Science'2008, Information Technology Journal, 7(6): 924-929.

[3] Wimalasundera Saman, 2006, "Computer Vision Syndrome”, Vol 11: No. 1. 2006.

[4] Namrata Arora Charpe and Vandana Kaushik, 2009. Computer Vision Syndrome (CVS): Recognition and Control in Software Professionals J Hum Ecol, 28(1): 67-6.

[5] Deni Setiawan. 2010. Analisis Kelelahan Mata Pekerja Sebelum Dan Sesudah Bekerja pada Intesitas Penerangan dibawah Standar di Ruangan Office PT. Buma Jobsite Adaro. Skripsi. Surakarta: Fakultas Kedokteran,Universitas Sebelas Maret Surakarta..

[6] Prasetyo Eko, 2010, Pengolahan Citra Digital dan Aplikasinya menggunakan MATLAB, Andi, Yogyakarta. 
[9] Putra Dharma, 2010, Pengolahan Citra Digital, Andi, Yogyakarta.

Digital, Andi, Yogyakarta.

[8] Kadir, Abdul., Adhi Susanto, 2013, Teori dan Aplikasi Pengolahan Citra, Penerbit Andi, Yogyakarta.
[10] Pranata, Andri. 2013. Analysis of Hough Transform Algorithm. Institut Teknologi Telkom Bandung. 